\title{
Interstitial Oxygen's Influence on the Corrosion Behavior of Ti-9Mo Alloys
}

\author{
R.A. Nogueira, L.M.C. Pinto ${ }^{\mathrm{b}}$, A.C.D. Ângelo ${ }^{\mathrm{b}}$, A.P.R.A. Claro $^{\mathrm{c}}$, C.R. Grandini ${ }^{\mathrm{a}}{ }^{\mathrm{a}}$ \\ ${ }^{a}$ Laboratório de Anelasticidade e Biomateriais, Universidade Estadual Paulista - UNESP, \\ CEP 17033-360, Bauru, SP, Brazil \\ ${ }^{\mathrm{b}}$ Laboratório de Eletrocatálise, Universidade Estadual Paulista - UNESP, \\ CEP 17033-360, Bauru, SP, Brazil \\ ${ }^{\mathrm{C}}$ Departamento de Materiais e Tecnologia, Universidade Estadual Paulista - UNESP, \\ CEP 12516-410, Guaratinguetá, SP, Brazil
}

Received: November 9, 2012; Revised: July 12, 2013

\begin{abstract}
Titanium and its alloys have been used in biomedical applications because of their satisfactory mechanical properties, biocompatibility and corrosion resistance. Their high corrosion resistance has been attributed to the formation of a thermodynamically stable titanium oxide layer on the surface of these materials. In the present work, the corrosion behavior of Ti-9Mo (wt \%) alloy, doped with oxygen, was evaluated in a phosphate buffered saline (PBS) solution. The results showed a small decrease in the corrosion potential and a reduction in the corrosion rate with the oxygen doping, indicating a higher corrosion resistance is desirable for biomedical applications.
\end{abstract}

Keywords: Ti alloys, corrosion, potentiostatic method, repassivation

\section{Introduction}

Biomaterials should provide higher biocompatibility, superior corrosion resistance in the body environment, a combination of high strength and low modulus, high fatigue and wear resistance, high ductility, and should not cause cytotoxicity ${ }^{1}$. Corrosion resistance is of fundamental importance in biocompatible alloys that are used for manufacturing orthopedic implants. This property does not determine only the device's useful life, but also the harmfulness of corrosion processes that occur in living organisms ${ }^{2}$. The low corrosion resistance of implants in body fluid results in the release of non-compatible metal ions by the implants into the body. The released ions are found to cause allergic and toxic reactions ${ }^{3}$. Titanium and its alloys offer superior corrosion resistance in several media including the human body environment. Their high corrosion resistance has been attributed to forming a thermodynamically stable titanium oxide layer on the surface ${ }^{4,5}$.

The use of metallic materials in aqueous media applications, such as the human body, results in the appearance of humidity-related corrosion phenomena, known as electrochemical processes ${ }^{6}$. The release of products of metallic corrosion and ions produced by electrochemical corrosion is cause for concern in biomedical applications of metals because of a possible cytotoxic effect ${ }^{7}$. Some metals and alloys under specific surrounding conditions lose their chemical reactivity and become inert. This phenomenon, known as passivity, is shown in chromium, iron, nickel, titanium, and several alloys of these metals.

The development of new methods for producing corrosion-resistant alloys requires tests that evaluate the

*e-mail: betog@fc.unesp.br materials' performance in a short interval of time. The most widely used and well-known electrochemical technique is the Tafel polarization curve, in which it is possible to obtain the corrosion potential $\mathrm{E}_{\text {corr }}$ and the corrosion current for each material in a specific medium ${ }^{8}$. Studies have been realized to evaluate the corrosion resistance of titanium alloys. In a previous work, corrosion resistance of Ti-10Mo experimental alloy in fluoridated physiological serum was studied and compared with Ti-6Al-4V alloy ${ }^{5}$. Similar electrochemical response has been obtained. In naturally aerated physiological serum, corrosion rate is mainly controlled by dissolution process of a complex passive film. Oliveira et al. ${ }^{9}$ studied the electrochemical behavior of commercially pure titanium (cp-Ti) and the Ti-Mo system's alloys (6-20\% in weight) with regard to immersion time in the electrolyte that simulates a physiological medium. The values of potential indicated that Ti-Mo alloys and cp-Ti present a titanium oxide layer that forms spontaneously.

Another electrochemical study was performed by Oliveira et al. ${ }^{10}$ for the Ti-Mo system (4-20 wt \%). Analysis of the electrochemical potential indicated the alloys present a spontaneous passivation. The studied samples had not presented corrosion for pitting (located) in potentials up to $8 \mathrm{~V}$, pointing to an increased corrosion resistance. The growth of anodic oxides samples showed that chloride ions during hard anodizing do not influence the stability of oxides. It also signals that adding molybdenum in $\mathrm{cp}$ Ti improves the stability of anodic oxides. Zhou et al. ${ }^{11}$ studied the corrosion behavior of $\alpha+\beta$ Ti-10Mo and $\beta$ Ti-20Mo (wt \%) alloys cold-rolled and heat-treated by studying the anodic polarization curves at $310 \mathrm{~K}$ in $5 \mathrm{~mol} \%$ hydrochloric acid solution to determine the potential use of those alloys in biomedical applications. The results showed 
the corrosion potential of these alloys shifts toward nobler performance when compared to cp-Ti. The results of current density suggest a high possibility that these alloys undergo passivation in the human body, as the tested solution simulates the body fluids, in accordance to other previous studies $^{5,12,13}$.

The crystal structure of Ti-Mo system is sensitive to Mo concentration. The volumetric fraction of the $\beta$ phase increases with an escalation of Mo quantity, thus decreasing the $\alpha$ phase's proportion and leading to an improvement in the corrosion behavior of these alloys ${ }^{14}$. The increase in the Mo concentration decreases the elasticity modulus. This element has higher melting point and density than $\mathrm{Ti}$, increasing the density and the Ti alloys' melting point, which is not desirable for biomaterials applications. Combining the advantages and disadvantages of $\beta$-type Ti alloys, it follows that alloys with a low concentration of $\beta$ stabilizing elements are required, since they have an excellent combination of low modulus, low melting point and low density. Molybdenum is an efficient $\beta$ stabilizer element because in lower concentrations it stabilizes the $\beta$ phase from the cooling ${ }^{11}$. According to this view, Ti-Mo system is one of the most suitable for applications as biomaterials. Several researchers have studied the corrosion behavior of Ti-10Mo and Ti-15Mo alloys ${ }^{5,9,10}$ with predominance of $\beta$ phase ${ }^{1}$. The Ti-9Mo has a large volumetric fraction of $\beta$ phase, but contains a small quantity of $\alpha$ phase, which is interesting for this study.

In this paper we shall show the investigation of the corrosion behavior of Ti-9Mo alloy used as a biomaterial, containing interstitial oxygen in solid solution, immersed in a PBS solution $(136 \mathrm{mM} \mathrm{NaCl} ; 2.7 \mathrm{mM} \mathrm{KCl} ; 6.5 \mathrm{mM}$ $\left.\mathrm{Na}_{2} \mathrm{HPO}_{4} ; 1.5 \mathrm{mM} \mathrm{KH}_{2} \mathrm{PO}_{4}[\mathrm{pH}=7.2]\right)^{15}$ in order to simulate the human body fluids.

\section{Experimental Details}

The Ti-9Mo alloy was produced from commercially pure titanium (99.9\%) and molybdenum (99.9\%) supplied by Aldrich Inc. Samples were melted in an arc-melting furnace under argon atmosphere and they were remelted ten times in order to improve chemical homogeneity ${ }^{5}$.

Chemical analysis of the Ti-9Mo samples after melting was realized in a Varian's Inductively Coupled Plasma Optical Emission Spectrometer (ICP-OES) ${ }^{16}$.

To evaluate the effect of interstitial oxygen in the Ti-9Mo alloy's corrosion behavior an annealing and an oxygen doping procedure was performed. For annealing, the temperature was increased up to $1100{ }^{\circ} \mathrm{C}$ in a vacuum of $1 \times 10^{-8} \mathrm{Torr}$, at a heating rate of $10^{\circ} \mathrm{C} / \mathrm{min}$, remaining in this temperature for $6 \mathrm{~h}$ and cooled up to room temperature without a pre-established rate (furnace cooling). For the oxygen doping, the temperature was increased up to $800{ }^{\circ} \mathrm{C}$, at a heating rate of $10{ }^{\circ} \mathrm{C} / \mathrm{min}$. At this temperature, a partial pressure of $1 \times 10^{-5}$ Torr of oxygen was introduced, remaining in these conditions for $30 \mathrm{~min}$. After that, fast water cooling up to room temperature was performed. A Residual Gas Analyzer accompanied the treatments, and none of the elements that compose the samples was lost during the above-mentioned processes. The samples were named TM \#1 (as received, after cold-work), TM \#2 (after cold-work and after heat treatment) and TM \#3 (after coldwork, heat treatment and oxygen doping).

Samples were characterized by $\mathrm{x}$-ray diffraction (XRD) measurements, using a Rigaku model D/MAX-2100PC, with $\mathrm{Cu} \mathrm{K} \alpha$ radiation, and by scanning electron microscopy (SEM) technique using a Leica Stereoscan 400 microscope. The samples were cold-rolled and cut to the final dimensions of $40 \mathrm{~mm} \times 2 \mathrm{~mm} \times 2 \mathrm{~mm}$. The surface of these alloys was mechanically polished via a standard metallographic procedure with waterproof emery papers up to 1500 grit under running water, and then polished with alumina and diamond paste. After that, the samples were etched in a solution of water, nitric acid, and fluoric acid (80:15:5 in volume $)^{17,18}$

The oxygen content was determined by inert fusion gas method and infrared detection ${ }^{19}$, using a HORIBA EMGA520 equipment. To evaluate the interstitial oxygen's effect in the samples' corrosion behavior, the variation of the electrochemical potential of these alloys was measured using an automatic Potentiostat-Galvanostat model 283 (EGG \& PAR), controlled by the M270 software. The Ti-9Mo samples were used as working electrodes in a meniscus configuration in a one-compartment electrochemical cell. The samples were examined with the same geometric superficial area, $4 \mathrm{~mm}^{2}$. A platinum wire was used as an auxiliary electrode and a silver wire, immersed in the PBS electrolyte solution, as a reference system. The measurements above were performed at room temperature $\left(25 \pm 1{ }^{\circ} \mathrm{C}\right)$ in the oxygen atmosphere.

For the electrochemical measurements all samples were submitted to the same pre-treatment as for SEM technique. The samples had been polished first with alumina and then diamond paste to remove grooves till a specular appearance and to ensure they leaned uniformly against the solution. Surveying the polarization curve data requires periodic monitoring of the potential over the course of 24 hours until the stabilization of the alloy's potential in solution. After this 24-hour period, the electrochemical cell was connected to the Potentiostat and the polarization curve was obtained. The measurements were carried out in the range of -500 to $+500 \mathrm{mV}$ from the potential obtained after stabilization, with a sweep rate of $0.2 \mathrm{mV} / \mathrm{s}$.

\section{Results and Discussion}

The results of chemical analysis of the Ti-9Mo samples after melting are shown in Table 1.

Table 2 shows the oxygen amount present in three Ti-9Mo samples. After annealing the oxygen content diminished considerably, TM \#1 sample present the higher content of oxygen. This can be explained by the oxygen present in the intergrain zone and that escapes with the annealing in Ultra-High-Vacuum (UHV). However, after doping, an increase in the oxygen concentration can be observed, from TM \#2 to TM \#3.

Figure 1 shows the XRD patterns for Ti-9Mo experimental alloy: as received, after annealing and doping with oxygen. There are no significant structural changes after the annealing and doping with oxygen in the alloy structure. A coexistence between two phases orthorhombic $\alpha$ ' ' and $\beta$ can be observed, pointing to the predominance of $\alpha$ '. The 
Table 1. Chemical composition of the Ti-9Mo samples.

\begin{tabular}{ccccc}
\hline Element & Mo & Si & Fe & Al \\
\hline (wt \%) & $(9.06 \pm 0.04)$ & $(0.14 \pm 0.01)$ & $(0.033 \pm 0.002)$ & $(0.12 \pm 0.01)$ \\
\hline
\end{tabular}

Table 2. Interstitial oxygen content of the Ti-9Mo samples used in this study.

\begin{tabular}{cccc}
\hline Sample & TM \#1 & TM \#2 & TM \#3 \\
\hline Oxygen $(w t \%)$ & $(0.178 \pm 0.005)$ & $(0.118 \pm 0.007)$ & $(0.149 \pm 0.005)$ \\
\hline
\end{tabular}

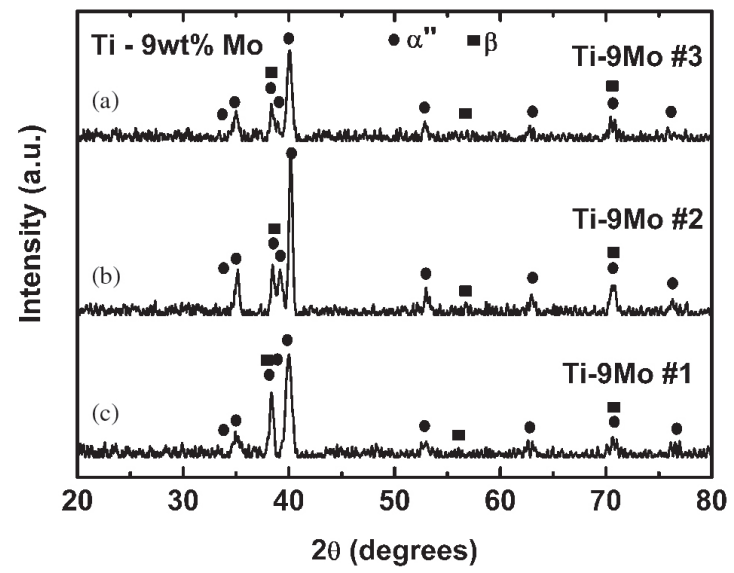

Figure 1. X-ray diffraction patterns for Ti-9Mo alloys (a) as received, (b) after annealing, and (c) after doping with oxygen.

results presented in this paper are similar to those obtained by Ho et al. ${ }^{17}$, Nogueira et al. ${ }^{20}$, and Oliveira et al. ${ }^{21}$. These authors made $\mathrm{x}$-ray diffraction measurements in Ti-10Mo alloys and found the coexistence of these two phases.

The microstructures of Ti-9Mo alloy in all three conditions studied are shown in Figure 2. The results for the as-received sample (TM \#1) are shown in Figure 2a, which clearly depicts the two phases observed in the X-ray measurements, the acicular martensitic orthorhombic structure ( $\alpha$ " phase) and the matrix with body centered cubic structure ( $\beta$ phase). A coexistence of two phases can also be observed in Figure $2 b$ and Figure $2 c$, the acicular martensitic $\alpha$ " and the retained $\beta$ phase.

Ho et al. ${ }^{17}$ studied the Ti-Mo system, and the results indicated the crystal structure of these binary alloys is sensitive to the composition (molybdenum content). When the molybdenum content is $6 \mathrm{wt} \%$, a predominance of the orthorhombic $\alpha$ " phase was observed in the cast alloy. When the molybdenum content is increased to $7.5 \mathrm{wt} \%$ only the $\alpha$ " phase was observed in the cast alloy. When the molybdenum content is increased to $9 \mathrm{wt} \%$, a significant amount of $\beta$ phase was retained. When the molybdenum content is increased to $10 \mathrm{wt} \%$ or higher contents, only the retained $\beta$ phase was observed. In this work, Ti-9Mo composition was evaluated and it can be observed that predominant phase is the $\alpha$ ", with martensitic orthorhombic structure. These results are in line with the results obtained by Ho et al. ${ }^{17}$.
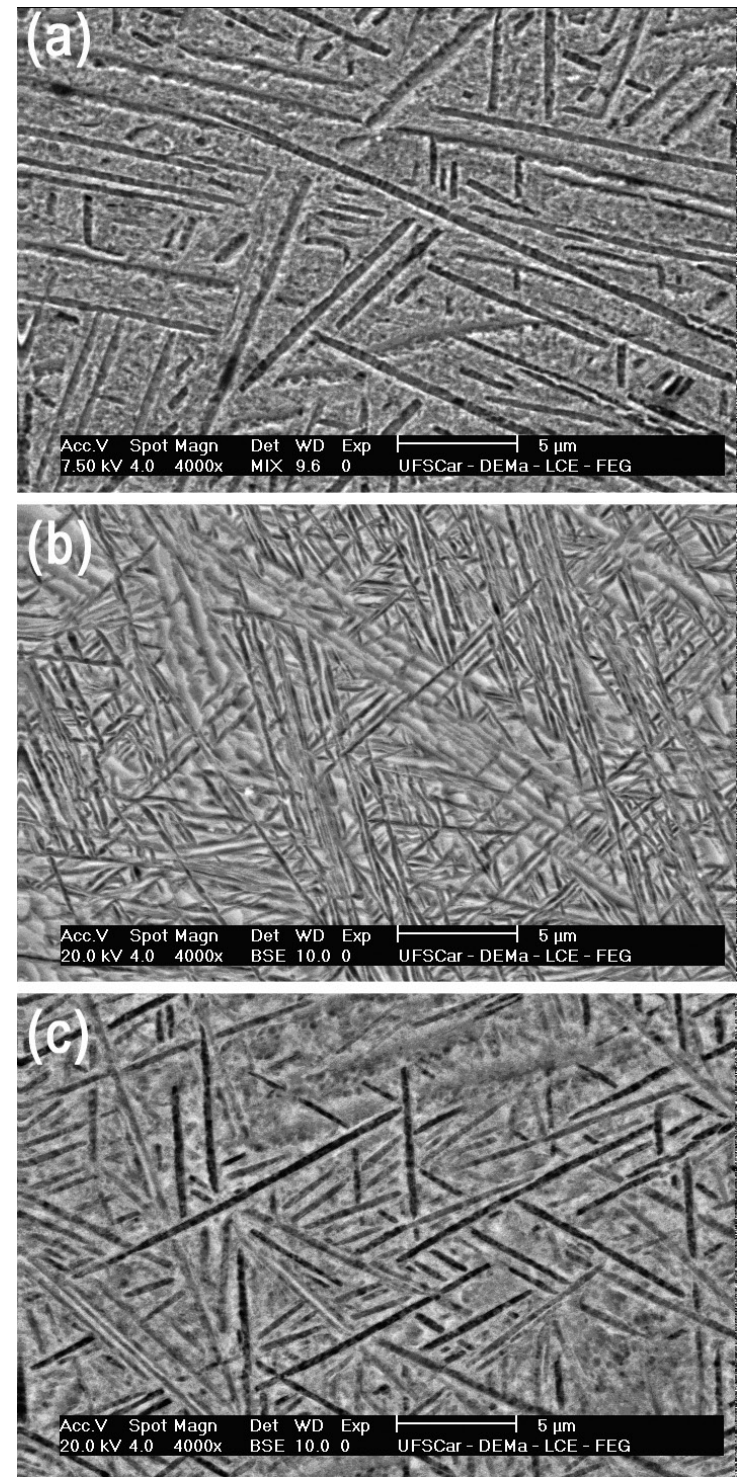

Figure 2. SEM micrographs of Ti-9Mo alloys, (a) as received, (b) after annealing, and (c) after doping with oxygen.

For the electrochemical measurements, the potential of the samples already immersed into the PBS solution was periodically monitored during a time period of 24 hours. This monitoring was carried out with a voltmeter, and the resulting curves are shown in Figure 3. This figure shows the variation of the open-circuit potential (OCP) of Ti-9Mo alloy with time in the PBS solution at $\mathrm{pH} 7.2$ at room temperature, in different conditions. At all conditions the potential changes toward a positive direction with time until the steady-state potential is reached. The observed equilibrium potentials are summarized in Table 3 .

The OCP's time profiles obtained for the samples shown in Figure 3 are similar, with samples TM \#2 and TM \#3 presenting basically the same value of potentials. Occurring different loads of oxygen allows for the same superficial structure's formation in the samples. In addition, increasing oxygen in the material may not affect the behavior of the 


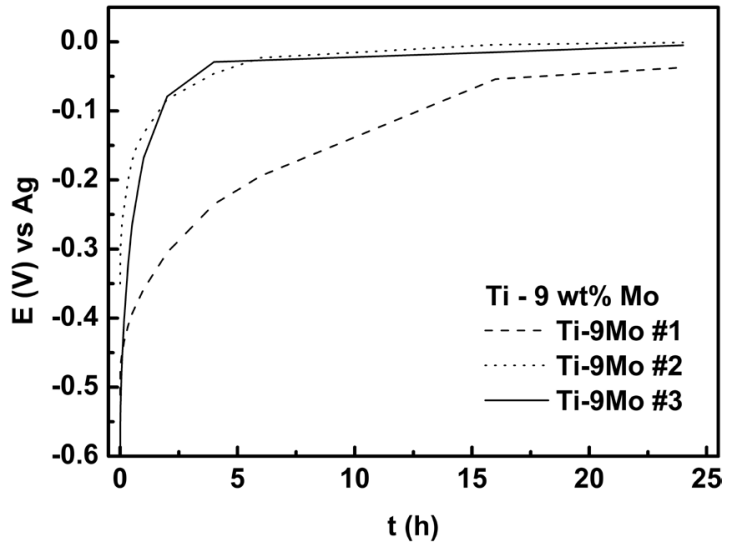

Figure 3. Potential variation with time for Ti-9Mo alloys in different conditions. Measurements carried out at room temperature $\left(25 \pm 1{ }^{\circ} \mathrm{C}\right)$.

Table 3. Corrosion potential and corrosion rate for Ti-9Mo with three different oxygen contents.

\begin{tabular}{lccc}
\hline \multicolumn{1}{c}{ Sample } & TM\#1 & TM\#2 & TM\#3 \\
\hline Equilibrium Potential $(\mathrm{V})$ & -0.037 & -0.001 & -0.005 \\
$\mathrm{E}_{\text {CORR }}(\mathrm{V})$ & -0.20 & -0.14 & -0.16 \\
$\mathrm{~J}_{\text {CORR }}\left(\mathrm{nA} / \mathrm{mm}^{2}\right)$ & 0.7 & 0.4 & 0.2 \\
\hline
\end{tabular}

electrochemical measurements. On the other hand, much higher loads of oxygen can "destroy" the material's structure, causing embrittlement. At first OCPs change quickly toward more positive potentials during the first hour, followed by stabilization observed in all the studied conditions; this suggests that a protective passive film is formed quickly on the metal surface in the artificial simulated media and remains stable during the entire immersion period. After the initial quick increase, $E$ changes slowly until it reaches a quasi-stationary value. Similar behavior was found by Cai et al. ${ }^{22}$ and Oliveira et al. ${ }^{9}$, where an initial increase in the $E$ during the early hours followed by stabilization were observed for all the specimens.

The resulting potentiodynamic polarization curve for TM \#1 as-received sample is shown in Figure 4. A passive region (Region 1) can be observed and that is followed by the breakdown of this passivation (Region 2) and then a posterior repassivation (Region 3 ) of the surface takes place. The same profile was already described by Cai et al. ${ }^{22}$ in a similar investigation of the electrochemical behavior of three cast titanium alloys with different surface conditions. Niemeyer et al. ${ }^{23}$ investigated Ti-13Nb-13Zr alloys with interstitial oxygen and also found a similar behavior. The simple exposure of the alloy to air may result in the formation of titanium oxide, considering that titanium presents great affinity to oxygen. The peak presented in Figure 4 at Region 2 is probably a rupture of this oxide film and the repassivation of the region. Normally, the break of that passivation occurs when the surface reaches a state of superior oxidation, forming a non-passivant oxide. The titanium oxide protects the bulk material and the nonoxidized metals, inhibiting their corrosion (oxidation) at

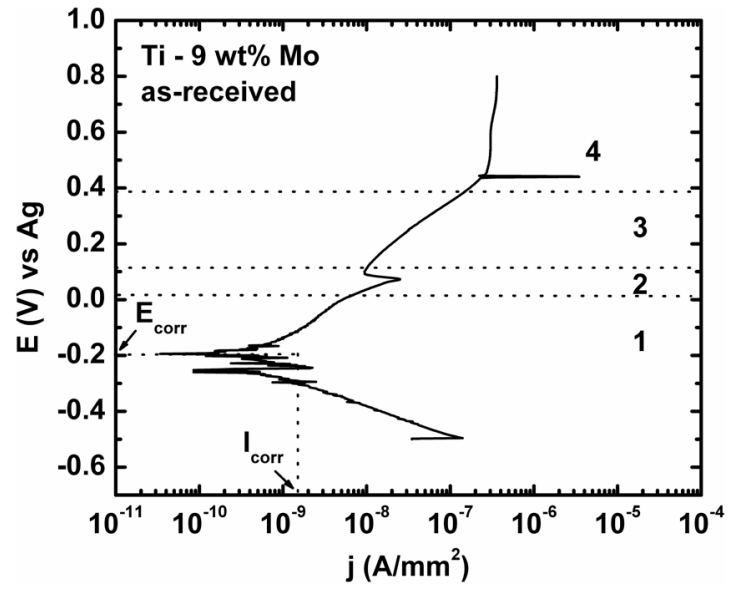

Figure 4. Potentiodynamic anodic polarization diagram of Ti-9Mo sample in as-received condition.

lower potentials. Thus, when the potential is increased, the preexisting oxide layer probably suffers rupture and the earlier non-oxidized metal is able to corrode, yielding an increase of the current. Some elements in the alloy can create another superficial passive layer that re-diminishes the current. For higher positive potentials there is a rupture of an oxide film in the metallic surface and the creation of another one of higher stability, as found in Region 4.

Figure 5 shows a comparison between the potentiodynamic anodic polarization curves for the Ti-9Mo alloys in the three investigated conditions, with different oxygen content. Qualitative analyses were made for the anodic polarization diagrams for each oxygen content. Polarization resistance and cathodic and anodic Tafel slopes were determined from the electrochemical experiment using the computer software. The corrosion rate $\left(\mathrm{I}_{\text {corr }}\right)$ and the corrosion potential $\left(\mathrm{E}_{\text {corr }}\right)$ of the alloys were determined, and the results are presented in Table 3 . These results were obtained by taking the cathodic and anodic tangents in the polarization curves.

It can be observed in Figure 5 the alloy with lower oxygen content (TM \#2) presents a nobler behavior. In other words, the lower-oxygen alloy has a higher corrosion potential in comparison with the other analyzed conditions, around $-0.14 \mathrm{~V}$. The alloy with the higher quantity of oxygen (TM \#1) has the worst corrosion potential of the studied alloys, around $-0.20 \mathrm{~V}$. The obtained values of corrosion potential for the Ti-9Mo alloy are better when compared to pure titanium ${ }^{4}$. This is in accordance with results found by Zhou et al. ${ }^{11}$ for the Ti-Mo alloys (10 and $20 \mathrm{wt} \%$ molybdenum), where the corrosion potential of these alloys shifts toward to more noble direction when compared to commercially pure Ti.

A small decrease in the value of corrosion potential occurred after doping with oxygen (TM \#3), to $-0.16 \mathrm{~V}$. Although this material requires less energy to corrode when compared to the material with lower oxygen concentration, this decrease is undesired when it comes to biomedical applications because the lower values of potential mean the corrosion process occurs easily (TM \#2). 


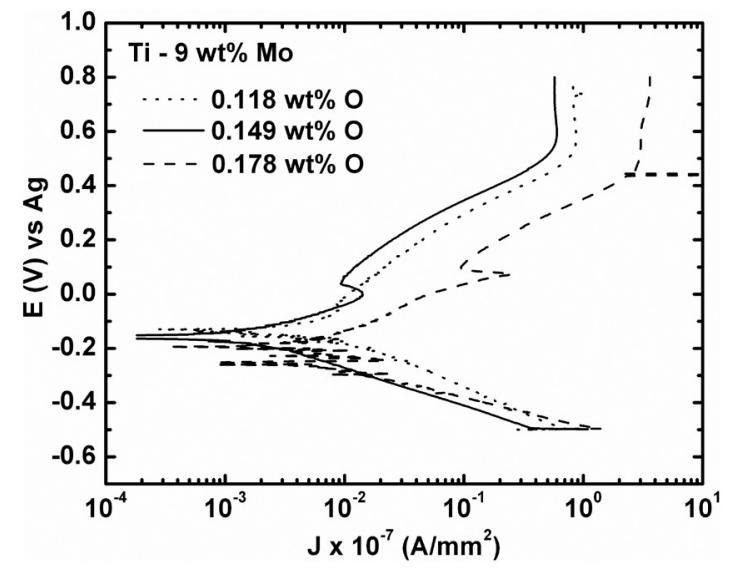

Figure 5. Potentiodynamic anodic polarization diagram of Ti-9Mo samples, with three different oxygen contents.

The corrosion rate is directly proportional to the corrosion current density. The three analyzed samples exhibit current density in the order of $\mathrm{nA} / \mathrm{mm}^{2}$. TM \#3 possesses the lower current density, but in the same order of magnitude as the other ones. The corrosion rate of Ti-9Mo alloy is next to that of pure titanium and in the same order of magnitude, around $10^{-10} \mathrm{~A} / \mathrm{mm}^{2[4,9]}$. The results of current density found for this alloy are similar to those found in the literature, suggesting that these alloys undergo passivation in the human body, since the test solution is a simulation of body fluids ${ }^{11}$.

\section{References}

1. Geetha M, Singh AK, Asokamani R and Gogia AK. Ti based biomaterials, the ultimate choice for orthopaedic implants - A review. Progress in Materials Science. 2009; 54:397-425. http://dx.doi.org/10.1016/j.pmatsci.2008.06.004

2. Metikos-Hukovic M, Kwokal A and Piljac J. The Influence of Niobium and Vanadium on Passivity of Titanium Based Implants in Physiological Solution. Biomaterials. 2003; 24:3765-3775. http://dx.doi.org/10.1016/S0142-9612(03)00252-7

3. Hallab NJ, Anderson S, Stafford T, Glant T and Jacobs JJ. Lymphocyte responses in patients with total hip arthroplasty. Journal of Orthopaedic Research. 2005; 23(2):384-391. http:// dx.doi.org/10.1016/j.orthres.2004.09.001

4. Geetha M, Kamachi Mudali U, Gogia AK, Asokamani R and Raj B. Influence of microstructure and alloying elements on corrosion behavior of $\mathrm{Ti}-13 \mathrm{Nb}-13 \mathrm{Zr}$ alloy. Corrosion Science. 2004; 46:877-892. http://dx.doi.org/10.1016/S0010938X(03)00186-0

5. Alves APR, Santana FA, Rosa LAA, Cursino SA and Codaro EN. A study on corrosion resistance of the Ti-10Mo experimental alloy after different processing methods. Materials Science and Engineering C. 2004; 24(5):693-696. http://dx.doi.org/10.1016/j.msec.2004.08.013

6. Kruger J. Fundamental Aspects of the Corrosion of Metallic Implant. In: Syrett BC and Acharya A, editors. Corrosion and Degradation of Implant Materials. Baltimore: American Society for Testing Materials; 1979. p. 107-127. http://dx.doi. org/10.1520/STP35940S

7. Kovacs P and Davidson JA. Chemical and Electrochemical Aspects of the Biocompatibility of Titanium and its Alloys.
Even with the low decrease of corrosion potential, the values of current density and the rate at which corrosion occurs have a significant decrease with oxygen doping (TM \#3), which indicates a higher resistance to corrode this material. This can be attributed to a greater stability achieved by the material because of oxygen doping. Increasing the oxygen concentration in the alloys raises the amount of this element in the crystal lattice. Therefore, the metal matrix's elements will react with less intensity with oxygen in the solution. Thus, the values decrease for the current density and the rate of corrosion from TM \#2 to TM \#3.

\section{Conclusions}

The electrochemical behavior of Ti-9Mo experimental alloy was investigated by OCP and potentiodynamic measurements. The results indicated the studied Ti9Mo alloys undergo spontaneous passivation because of spontaneously formed passivating oxide film on the metallic surface. With oxygen doping (TM \#3) a small decrease for corrosion potential and a significant diminished rate of corrosion was observed, which indicates a higher resistance of the material to corrosion in the simulated media. This is a desirable property for materials used in biomedical applications.

\section{Acknowledgments}

The authors wish to thank the Brazilian agencies Capes, $\mathrm{CNPq}$ and FAPESP for their financial support.

In: Brown AS and Lemons JE, editors. Medical Applications of Titanium and Its Alloys: The Material and Biological Issues. Ann Harbour: American Society for Testing Materials; 1996. p. 163-178. http://dx.doi.org/10.1520/STP16077S

8. Gentil V. Corrosão. Rio de janeiro: Livros Técnicos e Científicos; 1994.

9. Oliveira NTC and Guastaldi AC. Electrochemical stability and corrosion resistance of Ti-Mo alloys for biomedical applications. Acta Biomaterialia. 2009; 5(1):399-405. http:// dx.doi.org/10.1016/j.actbio.2008.07.010

10. Oliveira NTC and Guastaldi AC. Electrochemical behavior of Ti-Mo alloys applied as biomaterial. Corrosion Science. 2008; 50:938-945. http://dx.doi.org/10.1016/j. corsci.2007.09.009

11. Zhou Y-L and Luo D-M. Corrosion behavior of Ti-Mo alloys cold rolled and heat treated. Journal of Alloys and Compounds. 2011; 509:6267-6272. http://dx.doi.org/10.1016/j. jallcom.2011.03.045

12. Ho W-F. A comparison of tensile properties and corrosion behavior of cast Ti-7.5Mo with c.p. Ti, Ti-15Mo and Ti-6Al4V alloys. Journal of Alloys and Compounds. 2008; 464:580583. http://dx.doi.org/10.1016/j.jallcom.2007.10.054

13. Karayan AI, Park S-W and Lee K-M. Corrosion behavior of $\mathrm{Ti}-\mathrm{Ta}-\mathrm{Nb}$ alloys in simulated physiological media. Materials Letters. 2008; 62:1843-1845. http://dx.doi.org/10.1016/j. matlet.2007.10.028

14. Mareci D, Chelariu R, Gordin DM, Romas M, Sutiman D and Gloriant T. Effect of Mo content on electrochemical behaviour of TiMo alloys for dental applications. Materials 
and Corrosion. 2010; 61:829-837. http://dx.doi.org/10.1002/ maco. 201005761

15. Qi X-H, Mi J-Q, Zhang X-X and Chang W-B. Electrochemical studies on the interaction of morphine and its analogs with its antibody. Electrochemistry Communications. 2005; 7:227-232. http://dx.doi.org/10.1016/j.elecom.2005.01.001

16. American Society for Testing and Materials - ASTM. E237104: Standard Test Method for Analysis of Titanium and Titanium Alloys by Atomic Emission Plasma Spectrometry. ASTM; 2004.

17. Ho WF, Ju CP and Chern Lin JH. Structure and properties of cast binary Ti-Mo alloys. Biomaterials. 1999; 20:2115-2122. http://dx.doi.org/10.1016/S0142-9612(99)00114-3

18. American Society for Testing and Materials - ASTM. E-40707: Standard Practice for Microetching Metals and Alloys. ASTM; 2007.

19. American Society for Testing and Materials - ASTM. E140908: Standard Test Method for Determination of Oxygen and
Nitrogen in Titanium and Titanium Alloys by the Inert Gas Fusion Technique. ASTM; 2008.

20. Nogueira RA, Grandini CR and Claro APRA. Oxygen diffusion in Ti-10Mo alloys measured by mechanical spectroscopy. Journal of Materials Science. 2008; 43:5977-5981. http:// dx.doi.org/10.1007/s10853-008-2706-y

21. Oliveira NTC, Aleixo G, Caram R and Guastaldi AC. Development of Ti-Mo alloys for biomedical applications: Microstructure and electrochemical characterization. Materials Science and Engineering A. 2007; 452-453:727-731. http:// dx.doi.org/10.1016/j.msea.2006.11.061

22. Cai Z, Shafer T, Watanabe I, Nunn ME and Okabe T. Electrochemical characterization of cast titanium alloys. Biomaterials. 2003; 24:213-218. http://dx.doi.org/10.1016/ S0142-9612(02)00293-4

23. Niemeyer TC, Grandini CR, Pinto LMC, Angelo ACD and Schneider SG. Corrosion behavior of $\mathrm{Ti}-13 \mathrm{Nb}-$ $13 \mathrm{Zr}$ alloy used as a biomaterial. Journal of Alloys and Compounds. 2009; 476:172-175. http://dx.doi.org/10.1016/j. jallcom.2008.09.026 